\title{
BMJ Open Impact of cardiac resynchronisation therapy on burden of hospitalisations and survival: a retrospective observational study in the Northern Region of New Zealand
}

\author{
Khang-Li Looi, ${ }^{1}{ }^{1}$ Nigel Lever, ${ }^{1}$ Andrew Gavin, ${ }^{2}$ Robert Doughty ${ }^{1,3}$
}

To cite: Looi K-L, Lever N, Gavin A, et al. Impact of cardiac resynchronisation therapy on burden of hospitalisations and survival: a retrospective observational study in the Northern Region of New Zealand. BMJ Open 2019;9:e025634. doi:10.1136/ bmjopen-2018-025634

- Prepublication history for this paper is available online. To view these files, please visit the journal online (http://dx.doi org/10.1136/bmjopen-2018025634).

Received 25 July 2018 Revised 18 March 2019 Accepted 26 March 2019

Check for updates

(c) Author(s) (or their employer(s)) 2019. Re-use permitted under CC BY-NC. No commercial re-use. See rights and permissions. Published by BMJ.

${ }^{1}$ Green Lane Cardiovascular Service, Auckland City Hospital, Auckland, New Zealand

${ }^{2}$ Cardiovascular Division, North Shore Hospital, Auckland, New Zealand

${ }^{3}$ Department of Medicine, University of Auckland, Auckland, New Zealand

Correspondence to

Dr. Khang-Li Looi;

khanglil@adhb.govt.nz

\section{ABSTRACT}

Objective Cardiac resynchronisation therapy (CRT) devices have been shown to improve heart failure (HF) symptoms, survival and improve quality of life (QoL). We evaluated the overall impact of CRT on recurrent hospitalisations and survival in real-world patients with HF. Design Retrospective observational study.

Setting Northern region of New Zealand.

Participants Patients with HF who underwent CRT device implantation in between 2008 and 2014 were followed up for 1 year.

Interventions CRT.

Primary and secondary outcomes measured Survival, all-cause hospitalisations, length of stay, from which days alive and out of hospital (DAOH) were calculated.

Results 177patients were included, of whom eight died $(4.5 \%)$ within 1 year of follow-up. Pre-CRT implantation, $83 \%$ of all patients had been hospitalised for a total 248 hospitalisation events. Following CRT, 47 patients (27\%) were readmitted to hospital within 1 year (total of 98 admissions; $p<0.01$ compared with pre-device implant). Length of hospital stay was significantly shorter than in the year prior to CRT implantation at a median of 4 (IQR $2-6)$ vs 7 (IQR 3.5-10.5) days ( $p=0.03$ ). An increase in the median number of $\mathrm{DAOH}$ was observed from 362 (IQR 355-364) to 365 (IQR 364-365) $(p<0.01)$ after CRT implant. The improvement in DAOH was seen regardless of gender and type of CRT devices. Greater DAOH was also seen in those with non-ischaemic cardiomyopathy and Caucasians.

Conclusion After CRT implant, patients with HF have greater DAOH with reduction of total hospitalisation and fewer hospital days. These results support CRT devices use as a treatment option for appropriate HF patients. $\mathrm{DAOH}$ represents an easily measured, patient-centred endpoint that may reflect effectiveness of interventions in future CRT studies.

\section{INTRODUCTION}

Heart failure (HF) is a chronic and progressive condition. HF affects quality of life (QoL) more profoundly than many other chronic diseases. ${ }^{1}$ Symptom burden, the disabling
Strengths and limitations of this study

- Days alive and out of hospital (DAOH) is a new measurement that summarises the overall absolute treatment effect of cardiac resynchronisation therapy devices on the global burden of hospitalisation, morbidity and mortality in heart failure patients during follow-up.

DAOH reporting offers the advantage of providing information of value from different perspectives (ie, patients, tax-payers and the healthcare system).

- Small sample size of cohort with relatively short follow-up duration, ie, 1 year.

consequences of $\mathrm{HF}$ and the medication regimen (including side effects) all impact on the daily life of HF patients and contribute to impaired QoL. ${ }^{2}$ As the disease progresses, HF patients show a decline in QoL with increasingly frequent hospitalisations.

Cardiac resynchronisation therapy (CRT) devices have been shown to positively influence symptoms and improve QoL in selective group of patients with HF with left bundle branch block (LBBB). ${ }^{3}$ An analysis from the Cardiac Resynchronization-Heart Failure (CARE-HF) trial showed that CRT improved long-term QoL and survival in HF patients. ${ }^{4}$ At baseline, HF patients had a substantially lower mean European Quality of Life-5-Dimensions (EQ-5D) score than a representative age-matched general population $(0.60$ vs 0.78$).{ }^{4}$ Three months after randomisation, patients who received CRT had significant improvement in mean EQ-5D score (mean difference $0.08, \mathrm{p}<0.0001)$ compared with those assigned to medical therapy alone. CRT patients had a mean reduction in Minnesota Living with Heart Failure Questionnaire (MLHFQ) score of 10.6 points $(\mathrm{p}<0.001)$ at 3 months and this improvement was maintained 
throughout the study. ${ }^{4}$ These data support that CRT, in addition to medical therapy, in appropriate patients with HF improves symptoms and QOL that persist for several years.

\section{Objective}

The aim of our study was to describe the burden of hospitalisations, using the 'Days alive and out of hospital' (DAOH) in HF patients implanted with CRT devices in the Northern Region of New Zealand. ${ }^{5}$ We also aimed to determine whether DAOH differs by type of CRT devices, aetiology of $\mathrm{HF}$, gender or ethnicities.

\section{Study design and population}

This is a retrospective observational study. The study cohort consisted of consecutive patients implanted with CRT-capable devices between January 2008 to end of year 2014 in the Northern Region of New Zealand. All patients undergoing implantation of de novo CRT-pacemaker (CRT-P) and CRT-defibrillator (CRT-D), all upgrades from pacemakers to CRT-P or CRT-D, upgrades of implantable cardioverter defibrillators (ICD) to CRT-D using transvenous or epicardial left ventricular (LV) lead placement were included. The Northern Region of New Zealand is defined as the four northernmost District Health Board (DHB) areas. Patients undergoing CRT implantation who resided in the Auckland, Counties Manukau, Northland or Waitemata DHBs were included. The four DHBs in Northern Region serve 38\% of the total New Zealand population with estimated 1.76 million people in this region. ${ }^{6}$ New Zealand has a government-funded health system with universal coverage for all New Zealand residents that includes both acute and elective secondary and tertiary services. Currently there is no health insurance coverage for CRTs in New Zealand. All CRT implantation and follow-up is provided for by the public sector. The indications for CRT-D and CRT-P were based on the published 2010 New Zealand guidelines (box 1). ${ }^{7}$ All referrals for CRT were discussed by the orthern region implanting electrophysiologists regarding suitability and appropriateness of CRT support.

\section{Patient and public involvement}

This study is based on existing health system data with no direct patient and public involvement.

\section{Study design and data collection}

Every New Zealander has a National Health Index (NHI) number, a unique identifier that is assigned to each person who uses health and disability support services in New Zealand. Hospitalisation data for all patients was assessed using the administrative data of Ministry of Health and National Minimum Datasets (NMDS) inpatient hospitalisation data via NHI linkage up to end of year 2015. All-cause mortality data were collected using New Zealand mortality collection and NMDS.

Hospitalisation data for all patients were assessed for a full year prior to implantation (CRT-D or CRT-P) and after implantation or till death at the end of follow-up.
Box 1 New Zealand Primary Implantable Cardioverter Defibrillator Implantation and Cardiac Resynchronisation Therapy Guidelines

Recommendations for primary ICD implantation in New Zealand:

- Patients with ICM at least 1 month after acute MI or a NICM present for at least 3 months.

- $E F \leq 30 \%$ measured $\geq 3$ months after optimal heart failure treatment.

- NYHA class II or III.

- On maximal heart failure medications, including ACE inhibitors or angiotensin receptor blockers, beta-blockers and spironolactone as tolerated for at least 3 and preferably 6 months.

- No clinical symptoms or findings that would make them a candidate for a revascularisation procedure.

- At least 3 months remote from any revascularisation procedure.

- No associated disease with a likelihood of survival $<18$ months.

Age $\leq 75$ years.

Recommendations for cardiac resynchronisation therapy in New Zealand:

- $\mathrm{EF} \leq 35 \%$ after $\geq 6$ weeks of optimal heart failure treatment, with QRS duration is $>149 \mathrm{~ms}$ or is $120-149 \mathrm{~ms}$ with two additional criteria for dyssynchrony (aortic pre-ejection delay $>140 \mathrm{~ms}$, interventricular mechanical delay $>40 \mathrm{~ms}$ or delayed activation of the posterolateral left ventricular wall).

- NYHA class III.

- No major cardiovascular event in the prior 6 weeks and be in sinus rhythm.

- No major comorbidity reducing survival $<18$ months or seriously impairing quality of life.

$E F$, ejection fraction; ICD, implantable cardioverter defibrillator; ICM, ischaemic cardiomyopathy; MI, myocardial infarction; NICM, non-ischaemic cardiomyopathy; NYHA, New York Heart Association.EF, ejection fraction; ICD, implantable cardioverter defibrillator; ICM, ischaemic cardiomyopathy; MI, myocardial infarction; NICM, non-ischaemic cardiomyopathy; NYHA, New York Heart Association.

An admission was defined as a presentation to hospital requiring an overnight stay. Same day admissions were excluded to prevent influencing per admission length of stay. The total hospital days were calculated by adding the durations of each individual hospital admission to obtain days in hospital.

DAOH were calculated for each patient as follows ${ }^{5}$ : the total follow-up time was determined as number of days from device implant date until the date of the final patient examination (if alive) or end of follow-up date, ie, 1 year for the whole study cohort to ensure complete data ascertainment. The number of $\mathrm{DAOH}$ at 1 year were calculated using mortality and hospitalisation data from the date of implantation (to account for in-hospital mortality). Hence, DAOH is the difference between total follow-up time (ie, 1 year) and total time in hospital with number of days dead, where days dead refers to the number of days from death to the end of the assigned follow-up period (ie, 1 year), ie, DAOH=total follow-up time, ie, 1 year(total time in hospital +days dead).

For example, if a patient died during their index implant hospitalisation, they were assigned $0 \mathrm{DAOH}$ (figure 1A). If a patient was admitted for 5 days but then was not rehospitalised and survived to the end of the ascertainment period 

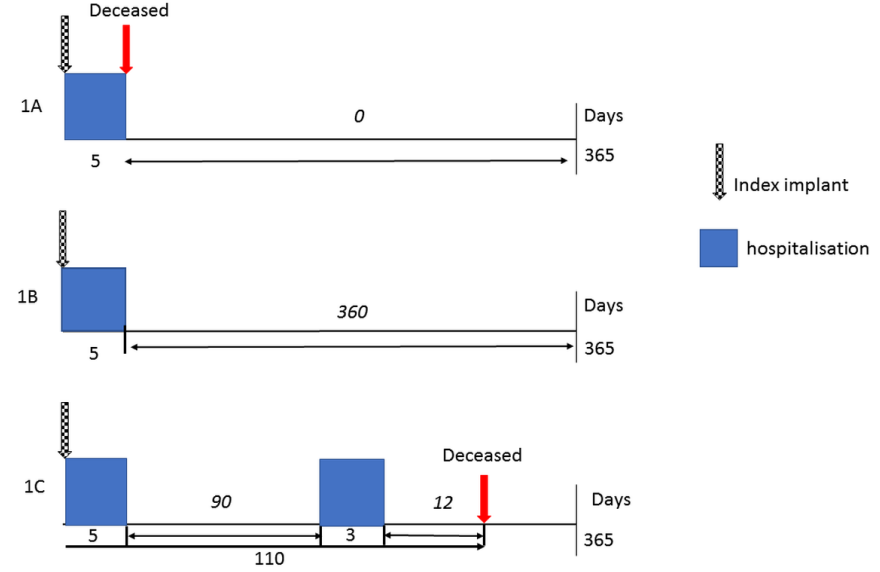

Figure 1 Examples of calculation of days alive and out of hospital.

(for instance 1year, ie, 365 days) they were assigned 360 $\mathrm{DAOH}$ (figure 1B). If a patient was admitted for 5 days, then rehospitalised for 3 days 90 days later then subsequently died at 110 days after their index hospitalisation, they were assigned $102 \mathrm{DAOH}$ (figure 1C).

\section{Statistical analysis}

All calculations were performed using SPSS V.25.0 (IBM Software). Baseline characteristics were summarised either as mean and SD (age and QRS duration), median and interquartile range (IQR) or frequency with percentage depending on the nature of the data. Comparison of continuous data was performed using the two-sample t-test. Length of hospital stay and DAOH were expressed as mean, median and IQR and compared using the Wilcoxon rank-sum test and Mann-Whitney test. A multivariate linear regression model was used to evaluate association between $\mathrm{DAOH}$ and baseline patient characteristics. A two-sided $p$ value $<0.05$ was considered statistically significant.

\section{RESULTS}

From 2008 to 2014, 177 patients were implanted with either CRT-D or CRT-P devices. Baseline characteristics of patients were shown in table 1: three-quarters of the patients were male and $81 \%$ Caucasians. CRT-D was the most common device implanted (82\%). Patients were more likely to have non-ischaemic cardiomyopathy (NICM) $(51 \%)$ with a mean left ventricular ejection fraction (LVEF) of $26 \% \pm 8 \%$. Twenty-six patients had permanent atrial fibrillation (AF) in whom 13 had had atrioventricular $(\mathrm{AV})$ nodal ablation. Shown in table 2 are the baseline characteristics of patients who received CRT-P and CRT-D. In general, patients receiving CRT-P were older, more likely to be female Caucasians, have pacemaker-induced cardiomyopathy but better LVEF, higher prevalence of permanent $\mathrm{AF}$ and previous history of AV nodal ablation, and have smaller body habitus than those who received CRT-D. Follow-up data were available for all patients, and eight patients $(4.5 \%)$ died within
Table 1 Baseline characteristics of patients implanted with CRT

$\mathrm{n}=177$

Median age (years) (IQR) 64.4 (57.5-70.6)

Gender

\begin{tabular}{|c|c|}
\hline Male (\%) & $135(76.3)$ \\
\hline Female (\%) & $42(23.7)$ \\
\hline \multicolumn{2}{|l|}{ Ethnicity (\%) } \\
\hline NZ European/other European & $143(80.8)$ \\
\hline Maori & $10(5.6)$ \\
\hline Pacific Island & $17(9.6)$ \\
\hline Asian & $7(4)$ \\
\hline \multicolumn{2}{|l|}{ Type of device } \\
\hline CRT-P & $32(18.1)$ \\
\hline CRT-D & $145(81.9)$ \\
\hline \multicolumn{2}{|l|}{ Aetiology } \\
\hline Ischaemic cardiomyopathy & $40(22.6)$ \\
\hline Non-ischaemic cardiomyopathy & $90(50.8)$ \\
\hline Pacing-induced cardiomyopathy & $32(18.1)$ \\
\hline Valvular heart disease & $6(3.4)$ \\
\hline Complex congenital heart disease & $2(1.1)$ \\
\hline Cardiac sarcoidosis & $4(2.3)$ \\
\hline Other causes & $3(1.7)$ \\
\hline Mean LVEF $(\% \pm S D)$ & $26.4 \pm 7.9$ \\
\hline NYHA functional class I/II/III & $\begin{array}{l}18(10 \%) / 79(45 \%) / \\
80(45 \%)\end{array}$ \\
\hline Median height (m) (IQR) & $1.74(1.67-1.78)$ \\
\hline Median weight (kg) (IQR) & $85.1(75.8-96.8)$ \\
\hline Median BMI (m/kg²) (IQR) & $28.3(25.5-32.2)$ \\
\hline Permanent AF (\%) & $26(15)$ \\
\hline Paroxysmal AF (\%) & $20(11.3)$ \\
\hline AV node ablation (\%) & $13(7.4)$ \\
\hline Diabetes mellitus (\%) & $42(23.7)$ \\
\hline Hypertension (\%) & $47(26.6)$ \\
\hline \multicolumn{2}{|l|}{ QRS morphology (\%) } \\
\hline LBBB & $135(76.3)$ \\
\hline Paced & $42(23.7)$ \\
\hline Mean QRS duration (ms) & $176.3 \pm 25.2$ \\
\hline Median eGFR (mL/min/1.73 $\left.\mathrm{m}^{2}\right)$ & 66 (54.5-85.5) \\
\hline
\end{tabular}

Stages of chronic kidney disease, n (\%)

\begin{tabular}{ll}
1 & $37(20.9)$ \\
2 & $84(47.5)$ \\
3 & $54(30.5)$ \\
4 & $2(1.1)$ \\
\hline
\end{tabular}

$\mathrm{AF}$, atrial fibrillation; $\mathrm{AV}$; atrioventricular; $\mathrm{BMI}$, body mass index; CRT, cardiac resynchronisation therapy; CRT-D, CRT with defibrillator; CRT-P, CRT with pacemaker; eGFR, estimated glomerular filtration rate; LBBB, left bundle branch block; LVEF, left ventricular ejection fraction; NYHA, New York Heart Association; NZ, New Zealand. 
Table 2 Baseline characteristics of patients implanted with CRT-D and CRT-P

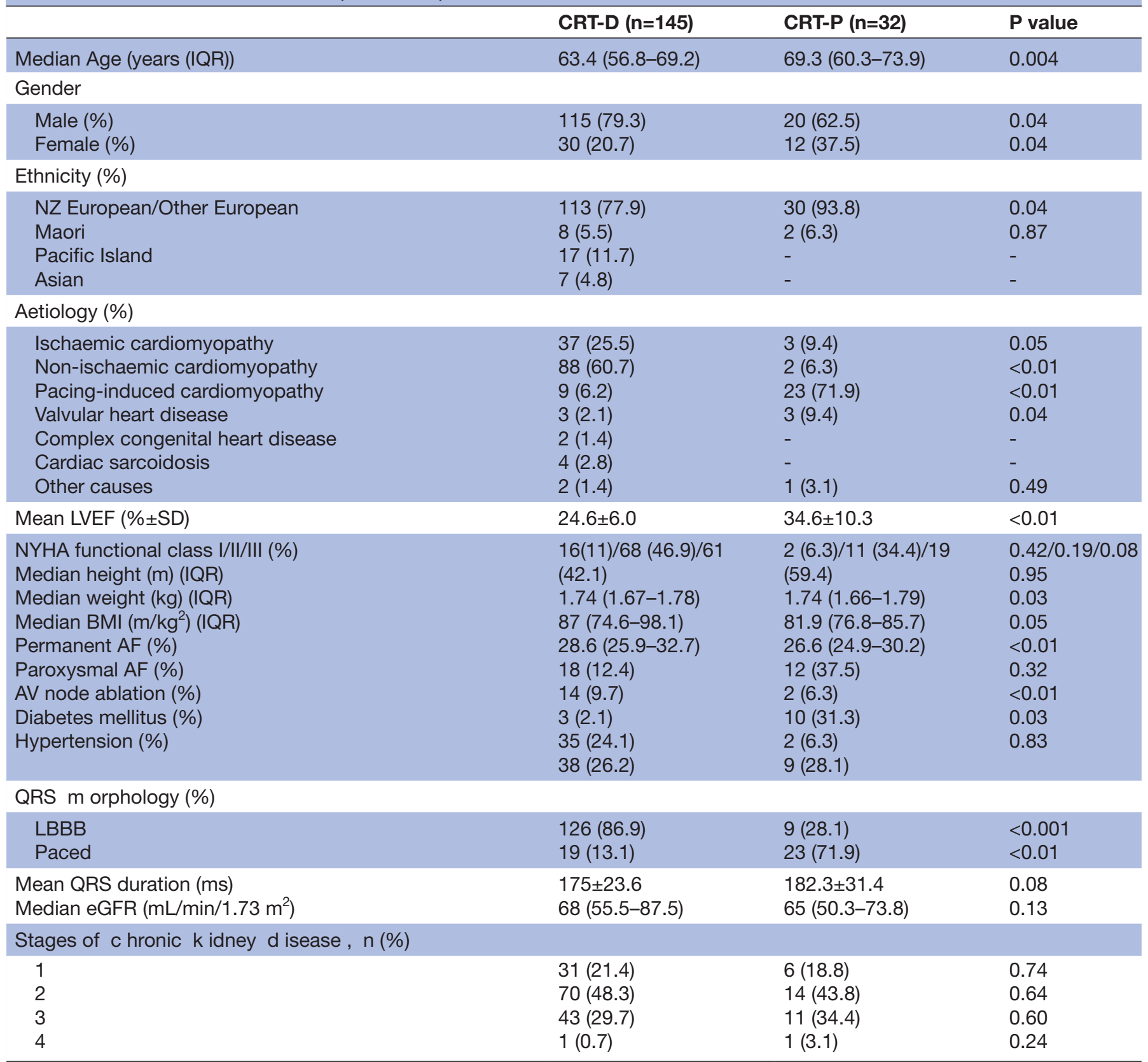

$\mathrm{AF}$, atrial fibrillation; AV, atrioventricular; BMI, body mass index; CRT-D, cardiac resynchronisation therapy with defibrillator; CRT-P, cardiac resynchronisation therapy with pacemaker; eGFR, estimated glomerular filtration rate; LBBB, left bundle branch block; LVEF, left ventricular ejection fraction; NYHA, New York Heart Association; NZ, New Zealand.

1 year (three were from HF deaths, and five from cardiovascular deaths attributable to myocardial infarction (MI) or cerebrovascular accidents).

\section{Hospitalisations}

Pre-CRT implantation, there were 248 hospitalisation events among $147(83.1 \%)$ patients. This resulted in total of 1126 hospital days with a median length of hospital day of 7 (3.5-10.5). After excluding implant admission (ie, all contiguous admissions preimplant and postimplant date and included interhospital transfers and periods of rehabilitation after implant prior to first discharge home), the number of total admissions post-CRT implant decreased to 98 episodes in 47 (26.6\%) patients after first discharge within the first-year follow-up $(p<0.01)$. Total hospital days had decreased from 1126 to 605 with a relative $46 \%$ reduction in total bed days. Length of hospital day was also significantly shorter than in the year prior to CRT implantation at a median of $4(2-6)(\mathrm{p}<0.01)$.

\section{Days alive and out of hospital prior and after device} implantation

Table 3 showed the DAOH of the whole study cohort and according to gender, ethnicity, aetiology of HF and type of devices. An increase in the median number of $\mathrm{DAOH}$ was observed from $362(355-364)$ to $365(364-365) \quad(\mathrm{p}<0.01)$ 
Table 3 Hospital admissions pre-CRT and post-CRT implantation at 1 year according to gender, ethnicity, aetiology of heart failure and type of devices

\begin{tabular}{|c|c|c|c|}
\hline Characteristics & 1 year prior to implant & 1 year postimplant & \multirow[b]{2}{*}{$P$ value } \\
\hline Total cohort $(n=177)$ & & & \\
\hline Total hospital admissions & 248 & 98 & $<0.01$ \\
\hline Total patient admitted & 147 & 47 & $<0.01$ \\
\hline Total hospital days & 1126 & 605 & $<0.01$ \\
\hline $\begin{array}{l}\text { Length of hospital stay (median (IQR) } \\
\text { days) }\end{array}$ & $7(3.5-10.5)$ & $4(2-6)$ & 0.03 \\
\hline $\mathrm{DAOH}($ median (IQR)) & $362(355-364)$ & $365(364-365)$ & $<0.01$ \\
\hline $\mathrm{DAOD}(\mathrm{mean} \pm \mathrm{SD})$ & $358.6 \pm 8.4$ & $354.7 \pm 44.8$ & 0.24 \\
\hline Number of deaths (\%) & 0 & $8(4.5)$ & not applicable \\
\hline \multicolumn{4}{|l|}{ Gender } \\
\hline \multicolumn{4}{|l|}{ Male $(n=135)$} \\
\hline Total hospital admissions & 193 & 78 & $<0.01$ \\
\hline Total patient admitted & 113 & 39 & $<0.01$ \\
\hline Total hospital days & 889 & 396 & $<0.01$ \\
\hline $\begin{array}{l}\text { Length of hospital stay days } \\
\text { (median (IQR) days) }\end{array}$ & $5(2.5-7.5)$ & $4(2-6)$ & 0.69 \\
\hline $\mathrm{DAOH}($ median (IQR)) & $362(355-364)$ & $365(363-365)$ & $<0.01$ \\
\hline $\mathrm{DAOH}($ mean $\pm \mathrm{SD})$ & $358.4 \pm 8.6$ & $354.5 \pm 45.7$ & 0.15 \\
\hline Number of deaths (\%) & 0 & $6(4.4)$ & not applicable \\
\hline \multicolumn{4}{|l|}{ Female $(n=42)$} \\
\hline Total hospital admissions & 55 & 20 & $<0.01$ \\
\hline Total patient admissions & 34 & 8 & $<0.01$ \\
\hline Total hospital days & 237 & 209 & $<0.01$ \\
\hline $\begin{array}{l}\text { Length of hospital stay (median (IQR) } \\
\text { days) }\end{array}$ & $3.5(2-5)$ & $7.5(4-11)$ & 0.14 \\
\hline $\mathrm{DAOH}($ median $(\mathrm{IQR}))$ & $363(354.8-364)$ & $365(365-365)$ & $<0.01$ \\
\hline $\mathrm{DAOH}(\operatorname{mean} \pm \mathrm{SD})$ & $359.4 \pm 7.8$ & $355.5 \pm 42.4$ & 0.39 \\
\hline Number of deaths (\%) & 0 & $2(4.8)$ & not applicable \\
\hline \multicolumn{4}{|l|}{ Ethnicity } \\
\hline \multicolumn{4}{|l|}{ NZ European/other European $(n=143)$} \\
\hline Total hospital admissions & 189 & 69 & $<0.01$ \\
\hline Total patient admitted & 118 & 35 & $<0.01$ \\
\hline Total hospital days & 813 & 389 & $<0.01$ \\
\hline $\begin{array}{l}\text { Length of hospital stay (median (IQR) } \\
\text { days) }\end{array}$ & $3.5(2-9)$ & $3(1.5-4.5)$ & 0.28 \\
\hline $\mathrm{DAOH}($ median $(\mathrm{IQR}))$ & $363(357-364)$ & $365(364-365)$ & $<0.01$ \\
\hline $\mathrm{DAOH}(\operatorname{mean} \pm \mathrm{SD})$ & $359.3 \pm 8.2$ & $357.1 \pm 40.2$ & 0.50 \\
\hline Number of deaths (\%) & 0 & $5(3.5)$ & not applicable \\
\hline \multicolumn{4}{|l|}{ Maori $(n=10)$} \\
\hline Total hospital admissions & 21 & 12 & 0.26 \\
\hline Total patient admitted & 10 & 4 & $<0.01$ \\
\hline Total hospital days & 128 & 76 & 0.35 \\
\hline $\begin{array}{l}\text { Length of hospital stay (median (IQR) } \\
\text { days) }\end{array}$ & $14.5(7-21)$ & $10(5-15)$ & 0.02 \\
\hline DAOH (median (IQR)) & $350(347.5-356)$ & $365(346-365)$ & 0.39 \\
\hline
\end{tabular}

Continued 


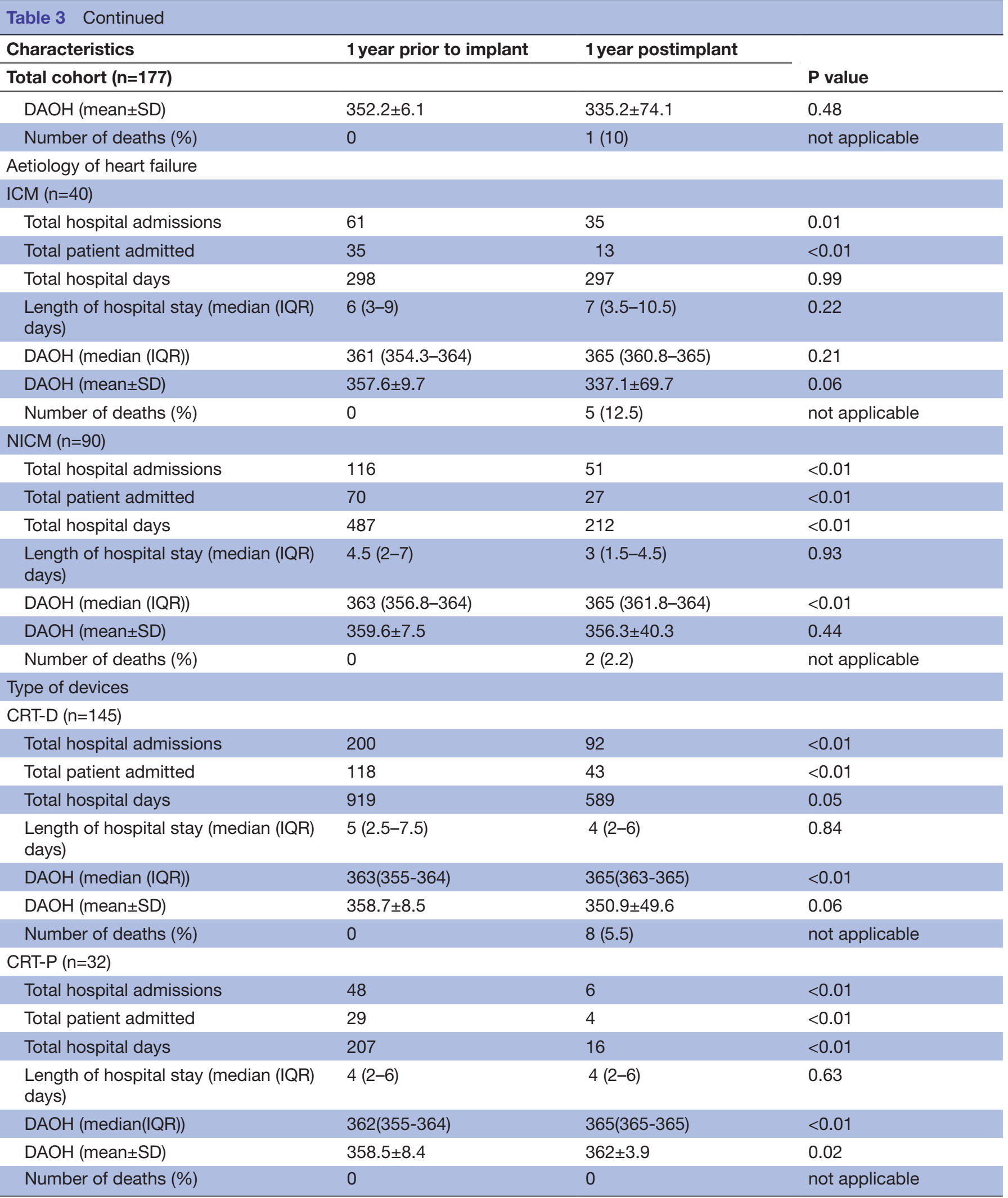

CRT, cardiac resynchronisation therapy; CRT-D, CRT with defibrillator; CRT-P, CRT with pacemaker; DAOH, days alive and out of hospital; ICM, ischaemic cardiomyopathy; NICM, non-ischaemic cardiomyopathy; NZ, New Zealand.

after CRT implant. Postimplant, the patients had significantly more time out of hospital than they did in the year prior to implant. This increase in $\mathrm{DAOH}$ was seen for both men and women, Caucasians, patients with NICM and both patients with CRT-D and CRT-P. For Māori patients, CRT implant was associated with reduction in 
total patient admissions and length of hospital stay but not $\mathrm{DAOH}$ (table 3 ).

\section{Influences of gender}

At the time of implant, median age between men and women was similar (64.4 (57.2-70.8) vs 64.9 (59.2-69.7) years, $\mathrm{p}=0.89)$. There were more CRT-P devices implanted in women $(28.6 \%$ vs $14.8 \%, \mathrm{p}=0.04)$. There was no difference in total hospital admissions, total hospital days, length of hospital days and $\mathrm{DAOH}$ between gender prior to implant (table 4). Postimplant, women had lower total hospital days (209 vs 396, $\mathrm{p}=0.04$ ) compared with men. However, the length of hospital day was longer in women compared with men $(7.5(4-11)$ vs 4 (2-6), $\mathrm{p}=0.03)$. There were no gender differences observed in $\mathrm{DAOH}$.

\section{Influences of type of devices}

CRT-D devices were the most common devices implanted in our study cohort (81.9\%).

CRT-D patients have more admissions prior to implant (118 vs $29, \mathrm{p}<0.01)$, and $38(26.2 \%)$ of these patients had either survived a cardiac arrest or had occurrence of symptomatic ventricular arrhythmias (table 4). At 1-year follow-up, CRT-D patients continued to have more total hospital admissions (92 vs $6, \mathrm{p}<0.01$ ), total hospital days (589 vs $16, \mathrm{p}=0.01)$ and shorter DAOH $(\mathrm{p}=0.04)$ compared with CRT-P patients. There were more deaths at follow-up in CRT-D group (8 vs $0, \mathrm{p}<0.01)$.

\section{Influence of aetiology of HF}

Among the cohort of patients, half (50.8\%) had underlying NICM and $22.6 \%$ had ICM. Patients with ICM were older (median age 66.1 (59.1-71.3) vs 62.8 (56.3-69.7), $\mathrm{p}=0.09$ ) but this was not statistically significant. Six patients with ICM died within 1 year compared with two with NICM (15\% and 2\% respectively; $\mathrm{p}<0.01)$. At 1-year follow-up, NICM patients had less total hospital days (212 vs 297, $\mathrm{p}<0.01)$ compared with those with ICM but there was no difference between total hospital admissions, total patient admissions, length of hospital day and $\mathrm{DAOH}$ (table 4).

\section{Influences of ethnicity}

The majority of the patients were Caucasians (80.8\%). Maori patients consisted of only a minority of CRT device recipients $(5.6 \%)$. Prior to implant, Maori patients have longer length of hospital stay (14.5 (7-21) vs 3.5 (2-9) days, $\mathrm{p}<0.01)$ and shorter DAOH (350 (347.5-356) vs $363(357-364), \mathrm{p}<0.01)$ compared with Caucasians (table 4).

At 1-year follow-up, there was no difference between the groups in terms of total hospital admissions $(\mathrm{p}=0.06)$, total patient admissions $(\mathrm{p}=0.15)$, total hospital days $(p=0.11)$, length of hospital stay $(p=0.22)$ and $\mathrm{DAOH}$ $(\mathrm{p}=0.23)$ between the two groups (table 4$)$.

Table 5 showed the results of multivariable linear regression that accounted for $20 \%$ of the variance in the difference between the DAOH prior and post CRT implant (adjusted R2=0.14, F $(17,159)=2.35, \mathrm{p}=0.030)$. A significant increase in DAOH was associated with higher QRS duration at implant among New York Heart Association (NYHA) class I patients $(\mathrm{p}=0.0065)$. Similarly, a significant reduction in $\mathrm{DAOH}$ was found for history of $\mathrm{AF}$ and ICM $(\mathrm{p}=0.0091)$.

\section{DISCUSSION}

We report here the burden of hospitalisations in a realworld cohort of patients with HF receiving CRT therapy. Prior to device implantation, the patients in our study had frequent hospitalisations. During 1-year post-CRT implantation, hospitalisations were reduced by two-thirds, length of hospital stay decreased and total bed days were virtually halved. Mortality rates were low and overall there was a significant increase in $\mathrm{DAOH}$.

Health-related QoL in patients with HF is an important outcome as it reflects the impact of HF on individual's daily lives. ${ }^{8}$ NYHA classification has been used traditionally to assess functional status in patients with HF. Although simple, it is subject to interobserver variability, captures only a limited range of health status and is applied from a physician's perspective instead of the patient's. ${ }^{9}$ The MLHFQ is a commonly used standard assessment instrument in clinical practice. ${ }^{10}{ }^{11}$ However, the MLHFQ does have limitations that include lack of responsiveness to clinical change and sensitivity when differentiating across different levels of HF symptom burden and objective measures of the functional capacity of the heart compared with NYHA and LVEF. ${ }^{12}$ The Kansas City Cardiomyopathy Questionnaire (KCCQ) is another self-administered, 23-item questionnaire that quantifies physical limitation, symptoms (frequency, severity and recent change over time), QoL, social interference and self-efficacy. KCQQ has been validated in stable and decompensated patients with $\mathrm{HF}$, and its sensitivity was substantially greater than that of the MLHFQ and the 36-Item Short Form Health Survey questionnaires. ${ }^{13}$ The KCCQ score also provides significant incremental predictive ability over NYHA for HF outcomes. ${ }^{14}$

Recurrent hospitalisations can adversely impact on QoL but assessing numbers or rates of admissions alone does not consider the overall burden of disease. DAOH could be used to measure QoL in patients with HF. ${ }^{5}$ It captures the number and duration of all hospitalisations as well as mortality, provides a readily comprehensible summary of treatment difference and therefore has the potential to add statistical power to detecting treatment differences. ${ }^{5}$ It also gives greater weight to the impact of survival: for example, if a patient has a short hospitalisation in week 1 because of worsening HF symptoms but survives and is not hospitalised for the remainder of their follow-up, they will have a greater $\mathrm{DAOH}$. A recent study by Boriani $e t a l$ reported the long-term 'real world' outcomes in patients with HF with ICDs and CRT-Ds devices using mortality, hospitalisations and DAOH. ${ }^{15}$ In this study, comorbidities were one of the key determinants of the $\mathrm{DAOH}$. By reporting $\mathrm{DAOH}$, this study has made it possible to assess 
Table 4 Comparison of hospital admissions and DAOH pre-CRT and post-CRT implantation between gender, ethnicity, aetiology of heart failure and type of devices

\begin{tabular}{|c|c|c|c|}
\hline & Male $(n=135)$ & Female $(n=42)$ & $P$ value \\
\hline Median age (IQR) & $64.4(57.2-70.8)$ & $64.9(59.2-69.7)$ & 0.89 \\
\hline \multicolumn{4}{|l|}{ Type of devices (\%) } \\
\hline $\begin{array}{l}\text { CRT-P } \\
\text { CRT-D }\end{array}$ & $\begin{array}{l}20(14.8) \\
115(85.2)\end{array}$ & $\begin{array}{l}12(28.6) \\
30(71.4)\end{array}$ & 0.04 \\
\hline Total hospital admissions prior & 193 & 55 & 0.4 \\
\hline Total patient admissions prior & 113 & 34 & 0.42 \\
\hline Total hospital days prior & 889 & 237 & 0.66 \\
\hline $\begin{array}{l}\text { Length of hospital days prior } \\
\text { (median (IQR)) }\end{array}$ & $5(2.5-7.5)$ & $3.5(2-5)$ & 0.53 \\
\hline DAOH prior (median (IQR)) & $362(355-364)$ & $363(354.8-364)$ & 0.52 \\
\hline $\mathrm{DAOH}$ prior $($ mean $\pm \mathrm{SD})$ & $358.4 \pm 8.6$ & $359.4 \pm 7.8$ & 0.67 \\
\hline Total hospital admissions post & 78 & 20 & 0.78 \\
\hline Total patients admissions post & 39 & 8 & $<0.01$ \\
\hline Total hospital days post & 396 & 209 & 0.04 \\
\hline $\begin{array}{l}\text { Length of hospital days post (median } \\
\text { (IQR)) }\end{array}$ & $4(2-6)$ & $7.5(4-11)$ & 0.03 \\
\hline DAOH after implant (median (IQR)) & $365(363-365)$ & $365(365-365)$ & 0.22 \\
\hline $\mathrm{DAOH}$ after implant (mean $\pm \mathrm{SD})$ & $354.5 \pm 45.7$ & $355.5 \pm 42.4$ & 0.89 \\
\hline \multirow{2}{*}{$\begin{array}{l}\text { Number of deaths at } 1 \text { year follow-up } \\
(\%)\end{array}$} & $6(4.4)$ & $2(4.8)$ & 0.86 \\
\hline & $\begin{array}{l}\text { NZ European/other } \\
\text { European }(n=143)\end{array}$ & Maori $(n=10)$ & $P$ value \\
\hline Median age (IQR) & $65.5(58.7-71.2)$ & $59.9(55.2-66.2)$ & 0.17 \\
\hline $\begin{array}{l}\text { Type of devices (\%) } \\
\text { - CRT-P } \\
\text { - CRT-D }\end{array}$ & $\begin{array}{l}30(21) \\
113(79)\end{array}$ & $\begin{array}{l}2(20) \\
8(80)\end{array}$ & 0.88 \\
\hline Total hospital admissions prior & 189 & 21 & 0.79 \\
\hline Total patient admissions prior & 118 & 10 & $<0.01$ \\
\hline Total hospital days prior & 813 & 128 & 0.68 \\
\hline $\begin{array}{l}\text { Length of hospital days prior } \\
\text { (median (IQR)) }\end{array}$ & $3.5(2-9)$ & $14.5(7-21)$ & $<0.01$ \\
\hline DAOH prior (median (IQR)) & $363(357-364)$ & $350(347.5-356)$ & $<0.01$ \\
\hline $\mathrm{DAOH}$ prior $($ mean $\pm \mathrm{SD})$ & $359.3 \pm 8.2$ & $352.2 \pm 6.1$ & 0.68 \\
\hline Total hospital admissions post & 69 & 12 & 0.06 \\
\hline Total patient admissions post & 35 & 4 & 0.15 \\
\hline Total hospital days post & 389 & 76 & 0.11 \\
\hline $\begin{array}{l}\text { Length of hospital days post (median } \\
\text { (IQR)) }\end{array}$ & $3(1.5-4.5)$ & $10(5-15)$ & 0.22 \\
\hline DAOH after implant (median (IQR)) & $365(364-365)$ & $365(346-365)$ & 0.23 \\
\hline $\mathrm{DAOH}$ after implant $(\operatorname{mean} \pm \mathrm{SD})$ & $357.1 \pm 40.2$ & $335.2 \pm 74.1$ & 0.01 \\
\hline \multirow{2}{*}{$\begin{array}{l}\text { Number of deaths at } 1 \text {-year follow-up } \\
(\%)\end{array}$} & $5(3.5)$ & $1(10)$ & 0.18 \\
\hline & ICM $(n=40)$ & $\operatorname{NICM}(n=90)$ & $P$ value \\
\hline Median age (IQR) & $66.1(59.1-71.3)$ & $62.8(56.3-69.7)$ & 0.09 \\
\hline $\begin{array}{l}\text { Type of devices (\%) } \\
\text { CRT-P } \\
\text { CRT-D }\end{array}$ & $\begin{array}{c}3(7.5) \\
37(92.5)\end{array}$ & $\begin{array}{c}2(2.2) \\
88(97.8)\end{array}$ & 0.04 \\
\hline
\end{tabular}


Table 4 Continued

\begin{tabular}{|c|c|c|c|}
\hline & ICM $(n=40)$ & NICM $(n=90)$ & $P$ value \\
\hline Total hospital admissions prior & 61 & 116 & 0.73 \\
\hline Total patient admissions prior & 35 & 70 & $<0.01$ \\
\hline $\begin{array}{l}\text { Length of hospital days prior } \\
\text { (median (IQR)) }\end{array}$ & $6(3-9)$ & $4.5(2-7)$ & 0.09 \\
\hline $\mathrm{DAOH}$ prior $(\operatorname{mean} \pm \mathrm{SD})$ & $357.6 \pm 9.7$ & $359.6 \pm 7.5$ & 0.09 \\
\hline Total hospital admissions post & 35 & 51 & 0.07 \\
\hline Total patient admissions post & 13 & 27 & 0.58 \\
\hline Total hospital days post & 297 & 212 & $<0.01$ \\
\hline $\begin{array}{l}\text { Length of hospital days post } \\
\text { (median (IQR)) }\end{array}$ & $7(3.5-10.5)$ & $3(1.5-4.5)$ & 0.55 \\
\hline \multirow{2}{*}{$\begin{array}{l}\text { Number of deaths at } 1 \text {-year follow-up } \\
(\%)\end{array}$} & 5 (12.5) & $2(2.2)$ & $<0.01$ \\
\hline & CRT-D (n=145) & CRT-P (n=32) & $P$ value \\
\hline Median Age (IQR) & $63.4(56.8-69.2)$ & $69.3(60.3-73.9)$ & 0.04 \\
\hline Total hospital admissions prior & 200 & 48 & 0.99 \\
\hline Total patient admissions prior & 118 & 29 & $<0.01$ \\
\hline Total hospital days prior & 919 & 207 & 0.82 \\
\hline $\begin{array}{l}\text { Length of hospital days prior } \\
\text { (median (IQR)) }\end{array}$ & $5(2.5-7.5)$ & $4(2-6)$ & 0.47 \\
\hline $\begin{array}{l}\text { Length of hospital days post (median } \\
\text { (IQR)) }\end{array}$ & $4(2-6)$ & $4(2-6)$ & 0.06 \\
\hline DAOH after implant (median (IQR)) & $365(363-365)$ & 365 (365-365) & 0.04 \\
\hline $\mathrm{DAOH}$ after implant $($ mean $\pm \mathrm{SD})$ & $350.9 \pm 49.6$ & $362 \pm 3.9$ & 0.01 \\
\hline Number of deaths at 1-year follow-up & $8(5.5)$ & 0 & $<0.01$ \\
\hline
\end{tabular}

CRT, cardiac resynchronisation therapy; CRT-D, CRT with defibrillator; CRT-P, CRT with pacemaker; DAOH, days alive and out of hospital; ICM, ischaemic cardiomyopathy; NICM, non-ischaemic cardiomyopathy; NZ, New Zealand.

the global burden of hospitalisation during follow-up, and enable us to summarise the absolute treatment effect of ICDs and CRT-Ds on mortality and morbidity. ${ }^{15}$

Assessing outcomes beyond survival is becoming increasingly important in an era where indications for CRT devices are expanding. DAOH puts emphasis on deaths occurring early in follow-up and captures the duration of all hospitalisations. In our study, patients implanted with CRT actually spent fewer days in hospital, with a reduction in total hospital bed-days over 1-year period (605 vs 1126 days, $\mathrm{p}<0.01$ ). Therefore CRT, using these measures of impact, has the potential not only for significant patient benefit but also reducing hospital costs as a result of the reduction of total hospitalisation and hospital bed-days with a greater $\mathrm{DAOH}$, ie, patients spent more time out of hospital alive.

We have shown that CRT implantation is associated with increase in $\mathrm{DAOH}$ regardless of gender and type of devices, consistent with previous studies that women derived similar benefits from CRT as men and CRT with or without ICD have major impact on morbidity and mortality. ${ }^{16-18}$ In our study, patients with NICM have less total hospitalisations, shorter length of hospital days and increased DAOH. NICM is a known predictor of better 
Table 5 Results of a multiple regression analysis predicting difference between the days alive and out of hospital prior and post-CRT implant

\begin{tabular}{llll}
\hline Variables & $\boldsymbol{\beta}$ & SE & P value \\
\hline Age at implant & -0.01 & 0.34 & 0.97 \\
\hline $\begin{array}{l}\text { NZ European (reference non- } \\
\text { European) }\end{array}$ & -9.99 & 9.46 & 0.29 \\
\hline Maori (reference non-Maori) & 10.1 & 15.3 & 0.56 \\
\hline Gender & 2.03 & 8.08 & 0.80 \\
\hline LVEF at implant & 0.07 & 0.46 & 0.87 \\
\hline eGFR at implant & -0.32 & 0.20 & 0.11 \\
\hline QRS Duration at implant & 0.14 & 0.15 & 0.35 \\
\hline ICM & -3.76 & 12.3 & 0.76 \\
\hline NICM & 2.34 & 10.34 & 0.82 \\
\hline Type of devices & 10.55 & 11.96 & 0.38 \\
\hline Primary prevention & -11.54 & 8.32 & 0.17 \\
\hline NYHA class I (reference class & 144.89 & 60.97 & 0.01 \\
II) & & & 0.45 \\
\hline NYHA class III (reference class & 4.91 & 6.93 & 0.70 \\
II) & -3.38 & 8.81 & 0.67 \\
\hline History of AF & -5.87 & 13.68 & $<0.01$ \\
\hline History of AV node ablation & -43.46 & 16.46 & $<0.01$ \\
\hline History of AF*ICM & 0.99 & 0.36 & \\
\hline $\begin{array}{l}\text { NYHA class I*QRS duration at } \\
\text { implant }\end{array}$ & & & \\
\hline P. & & & \\
\hline
\end{tabular}

$\beta$, standardised coefficients beta; $A F$, atrial fibrillation; AV, atrioventricular; CRT, cardiac resynchronisation therapy; eGFR, estimated glomerular filtration rate; ICM; ischaemic cardiomyopathy; LVEF, left ventricular ejection fraction; NICM, non-ischaemic cardiomyopathy; NYHA, New York Heart Association; SE, coefficient SEs; NZ, New Zealand.

response to CRT, thus our findings are consistent with published data. ${ }^{19}{ }^{20}$ In our study, there was no difference in total hospital days and length of stay post CRT implant in patients with ICM despite the reduction in hospitalisations. This could be explained by the fact that patients with ICM had more comorbidities (older, more cardiac arrest and lower LVEF). Patients with ICM have more vascular risk factors and therefore have high probabilities of staying in hospital for other interventions. This could also affect the total hospital days and length of stay. They also have more CRT-D devices implanted. Despite improvement in DAOH after implant, CRT-D patients still had more total hospital admissions, total hospital days and shorter DAOH compared with those with CRT-P. About $26 \%$ of these ICM patients with CRT-D had had suffered a cardiac arrest or symptomatic ventricular arrhythmias. There is also cumulative evidence that implanting CRT-D devices is associated with a higher perioperative and postoperative risk of major complications compared with CRT-P. ${ }^{21}{ }^{22}$ Almost 2/3 of CRT-P patients have pacemaker-induced cardiomyopathy. An upgrade to CRT can potentially prevent the reverse remodelling associated with chronic right ventricular pacing. Response to CRT further decreases the risk for ventricular arrhythmias, sudden cardiac death and all-cause mortality. All these factors likely account for the differences in DAOH between the two groups.

For Maori patients with HF, CRT implant was associated with reduction in total patient admissions and length of hospital stay but not DAOH (table 3). Compared with the Caucasian patients, the median length of hospital stay was longer and the median DAOH $(p<0.01)$ was shorter prior to CRT implant. Post CRT implant, these were not statistically significant. Maori patients in generally are disproportionately represented in adverse health outcomes with higher rates of admission and mortality from HF when compared with the non-Maori population. ${ }^{23}$ However, the number of Maori patients with CRT in our study was small. Additional studies with a larger number of Maori patients are needed to determine if there are other unmeasured confounders that might contribute to ethnicity differences and outcomes in our population. Taking socio-economic factors into account in future studies, not only ethnicity, would also allow to clarify the reasons of such differences noted.

Two pairs of clinical variables were found with significant interactions: (1) NYHA class I symptoms and QRS duration at implant and (2) History of AF and ICM. A significant increase in $\mathrm{DAOH}$ was associated with higher QRS duration at implant among NYHA class I patients. 
NYHA class I patients have minimal HF symptoms, therefore the chance of hospitalisation will be much reduced. QRS duration has been used as an enrolment criterion in multiple CRT clinical trials. Response to CRT seems to increase as the QRS duration becomes longer, with greatest benefit in QRS duration $\geq 150 \mathrm{~ms}$. In the Comparison of Medical Therapy, Pacing, and Defibrillation in Heart Failure (COMPANION) study, CRT-D was better than optimal HF therapy at all QRS durations, although the effect was greater with increasing QRS duration. ${ }^{17}$ CRT-P benefited those with QRS duration $\geq 150 \mathrm{~ms}^{17}$ In the CARE-HF study, CRT therapy was better than pharmacological therapy alone at all QRS durations, although the benefit was greater in those with a QRS duration $\geq 160 \mathrm{~ms}^{16}$ Similarly, in Multicenter Automatic Defibrillator Implantation Trial with Cardiac Resynchronization Therapy (MADIT-CRT), the benefit of CRT-D compared with an ICD alone was confined to those with QRS duration $\geq 150 \mathrm{~ms}^{24}$

The multivariable analyses for prediction of $\mathrm{DAOH}$ demonstrated that history of AF and the presence of ICM was associated with lower DAOH. In our study, there was no difference in DAOH post CRT implant in patients with ICM despite the reduction in hospitalisations as these patients have more comorbidities with high probabilities of staying in hospital for other interventions. The benefits of CRT appear to be attenuated in patients with AF. They exhibit loss of AV synchronicity, a higher risk for insufficient CRT delivery because of uncontrolled ventricular rates, inappropriate ICD shocks, inadequate symptomatic improvement, repeated hospitalisation and increased mortality. ${ }^{2526}$ Furthermore, in patients with AF, phases of effective biventricular capture alternate with phases of competing AF rhythm, which causes spontaneous, fusion or pseudofusion beats. ${ }^{27}$ Such beats render the pacing counters inaccurate for assessing true biventricular capture beats. The combination of these two variables would result in lower DAOH.

HF adversely affects QoL in HF patients and results in significant morbidity and mortality. ${ }^{28}$ CRT has been shown in multiple studies to improve symptoms, QoL and survival in patients with $\mathrm{HF}$ who remain symptomatic despite optimal medical therapy, and who have LVEF $\leq 35 \%$ and LBBB with QRS width $\geq 120 \mathrm{~ms}^{16}{ }^{17} 29$ Although the mortality was low post-CRT implant in our study, it was still $4.5 \%$ at 1 year. CRT is an expensive therapy. Given the limited resources in New Zealand and the high upfront costs of CRT devices, identifying appropriate patients with HF most likely to benefit from a CRT device is essential.

\section{Limitations}

This was a single-centre, retrospective observational study with relatively low sample size. We have recently published trends of CRT therapy use for eligible patients with $\mathrm{HF}$ in New Zealand and the data suggests that there is a significant unmet clinical need for CRT implantation in the Northern Region. ${ }^{30}$ Affordability and capacity are of concern in this region. Considering current workforce, funding constraints and the conservative approach taken, the published 2010 New Zealand guidelines (box 1) have more restrictive recommendations for CRT. This could all result in the low sample size. Our data do not provide specific information on the type of hospitalisation (HF-related vs non-HF-related) prior and post CRT implantation and on the different aspects of non-hospital HF management such as outpatient HF clinics or the use of pharmacotherapy after discharge.

Our study has not included comparison between CRT-responders versus non-responders. There are a significant number of current issues that exist when assessing CRT response. Firstly, the CRT response definition is highly dependent on the criteria used to define the response. ${ }^{31}$ The response rates tend to be higher when clinical measures, such as subjective measurements, ie, NYHA class, are used but are much lower when remodelling or outcome measurements are used. ${ }^{32}$ There is no consensus on the optimal timeline to assess response in clinical trials that involved CRT. Secondly, response criteria may vary greatly among investigators in different trials. Thirdly, multiple different factors between individual patients can affect the CRT response. In addition, it is unknown which CRT response definition, ie, improvement in clinical symptoms or LV reverse modelling will result in overall improved survival.

Another limitation is the short follow-up period used in our study (1 year). Boriani et al reported in a study on ICD and CRT-D implantations with a follow-up of minimum 3 years and maximum 8 years has suggested that studies with even longer follow-up could beneficially use $\mathrm{DAOH}$ and themselves advocate the calculation of DAOH 'from administrative databases with full coverage of long follow-up periods'. ${ }^{15}$ Although the results of some studies indicate gradual improvement in the QoL up to 2 years after CRT, others have reported high fluctuations (improvement and deterioration over the course of several months) in the first year after CRT. ${ }^{33}{ }^{34}$ Huynh et al reported the results of 382 patients with HF (61\% male, median age 75 years) from the MARATHON study in Australia that compare predictors of 30 day readmission or death with those of an alternative outcome in HF, DAOH within 12 months of discharge, which incorporates mortality and all hospitalisations into a single measure. ${ }^{35}$ The study showed that median DAOH within 12 months was 350 days (IQR 302-363). The final predictive model of DAOH included NYHA classification $(\mathrm{r}=-0.29, \mathrm{p}<0.001)$, $\mathrm{LV}$ volume index $(\mathrm{r}=-0.27, \mathrm{p}<0.001)$, $\mathrm{LA}$ volume index $(\mathrm{r}=-0.26, \mathrm{p}<0.001)$, presence of CKD $(\mathrm{r}=-0.22, \mathrm{p}=0.007)$, cognitive function using Montreal Cognitive Assessment (MoCA) score $(r=0.21, p<0.001)$ and presence of life-threatening arrhythmia $(\mathrm{r}=-0.16, \mathrm{p}=0.002)$ and this model of $\mathrm{DAOH}$ was more predictive than the risk score of 30 day readmission or death. ${ }^{35}$ Therefore, DAOH provides a valuable tool to estimate longevity and QoL in HF even the follow-up duration was short. In our study, patients implanted in 'real world' clinical practice with 
CRT device have, a relatively favourable improvement within a year of the implant. It is also difficult to compare patients before and after CRT implant as most of our patients would be hospitalised with their index event leading causing HF in the year prior to the implantation. The main strength of our study was the ability to assess the global burden of hospitalisation during follow-up, combining data with DAOH summarising the overall impact of CRT on HF mortality and morbidity.

\section{CONCLUSION}

Patients with HF implanted with CRT have greater DAOH within 1-year follow-up. The use of $\mathrm{DAOH}$ provides an alternative method for measuring the overall positive impact of CRT on HF mortality and morbidity. This technique may have more utility in assessing treatment impact generally compared with crude mortality or other measures of morbidity or change in function and warrants further testing in larger HF and CRT patient cohorts.

Acknowledgements We thank Charlene Nell, Desktop Support Team Administrator at Green Lane Cardiovascular Service/Cardiology Department, for her secretarial support and Eliazar Dimalapang, biostatistician at the Green Lane Cardiovascular Service/Cardiology Department for his valuable comments in the statistical analysis of the data.

Contributors RND contributed the conception and design of the study. KLL involved in data collection, data analysis and interpretation as well as writing of manuscript and developing the structure and arguments for the manuscript. AG, NL and RND involved in critical appraisal and revision of the manuscript. All authors read and approved the final manuscript.

Funding The authors have not declared a specific grant for this research from any funding agency in the public, commercial or not-for-profit sectors.

Competing interests None declared.

Patient consent for publication Not required.

Ethics approval This study was approved by the Central Health and Disability Ethics Committee (Ethics ref: 15/CEN/58/AM02).

Provenance and peer review Not commissioned; externally peer reviewed.

Data sharing statement No additional data are available.

Open access This is an open access article distributed in accordance with the Creative Commons Attribution Non Commercial (CC BY-NC 4.0) license, which permits others to distribute, remix, adapt, build upon this work non-commercially, and license their derivative works on different terms, provided the original work is properly cited, appropriate credit is given, any changes made indicated, and the use is non-commercial. See: http://creativecommons.org/licenses/by-nc/4.0/.

\section{REFERENCES}

1. Ahluwalia SC, Gross CP, Chaudhry SI, et al. Impact of comorbidity on mortality among older persons with advanced heart failure. J Gen Intern Med 2012;27:513-9.

2. Jaarsma T, Johansson P, Agren S, et al. Quality of life and symptoms of depression in advanced heart failure patients and their partners. Curr Opin Support Palliat Care 2010;4:233-7.

3. Dickstein K, Vardas PE, Auricchio A, et al. Focused Update of ESC Guidelines on device therapy in heart failure. European Journal of Heart Failure 2010;2010:1143-53.

4. Cleland JG, Calvert MJ, Verboven Y, et al. Effects of cardiac resynchronization therapy on long-term quality of life: an analysis from the CArdiac Resynchronisation-Heart Failure (CARE-HF) study. Am Heart J 2009;157:457-66.

5. Ariti CA, Cleland JG, Pocock SJ, et al. Days alive and out of hospital and the patient journey in patients with heart failure: Insights from the candesartan in heart failure: assessment of reduction in mortality and morbidity (CHARM) program. Am Heart J 2011;162:900-6.
6. Statistics New Zealand. District Health Boards Ethnic Group Population Projections, 2014-43 (2013-Base) - 2016 Update. Wellington: Statistics New Zealand, 2016.

7. Smith W. New Zealand Pacing and Electrophysiology Group. New Zealand primary implantable cardioverter defibrillator implantation and biventricular pacing guidelines. N Z Med J 2010;123:86-96.

8. Heo S, Moser DK, Riegel B, et al. Testing the psychometric properties of the Minnesota Living with Heart Failure questionnaire. Nurs Res 2005;54:265-272.

9. Raphael C, Briscoe C, Davies J, et al. Limitations of the New York Heart Association functional classification system and self-reported walking distances in chronic heart failure. Heart 2007;93:476-82

10. Rector TS, Cohn JN. Assessment of patient outcome with the Minnesota Living with Heart Failure questionnaire: reliability and validity during a randomized, double-blind, placebo-controlled trial of pimobendan. Pimobendan Multicenter Research Group. Am Heart J 1992;124:1017-25.

11. Garin O, Ferrer M, Pont A, et al. Disease-specific health-related quality of life questionnaires for heart failure: a systematic review with meta-analyses. Qual Life Res 2009;18:71-85.

12. Bennett SJ, Oldridge NB, Eckert GJ, et al. Comparison of quality of life measures in heart failure. Nurs Res 2003;52:207-16.

13. Green CP, Porter CB, Bresnahan DR, et al. Development and evaluation of the Kansas City Cardiomyopathy Questionnaire: a new health status measure for heart failure. J Am Coll Cardiol 2000;35:1245-55.

14. Hawwa N, Vest AR, Kumar R, et al. Comparison Between the Kansas City Cardiomyopathy Questionnaire and New York Heart Association in Assessing Functional Capacity and Clinical Outcomes. J Card Fail 2017;23:280-5.

15. Boriani G, Berti E, Belotti LM, et al. Cardiac device therapy in patients with left ventricular dysfunction and heart failure: 'real-world' data on long-term outcomes (mortality, hospitalizations, days alive and out of hospital). Eur J Heart Fail 2016;18:693-702.

16. Cleland JG, Daubert JC, Erdmann E, et al. The effect of cardiac resynchronization on morbidity and mortality in heart failure. $N$ Engl $J$ Med 2005;352:1539-49.

17. Bristow MR, Saxon LA, Boehmer J, et al. Cardiacresynchronization therapy with or without an implantable defibrillator in advanced chronic heart failure. $N$ Engl J Med 2004;350:2140-50.

18. Brignole M, Auricchio A, Baron-Esquivias G, et al. ESC guidelines on cardiac pacing and cardiac resynchronization therapy: the task force on cardiac pacing and resynchronization therapy of the European Society of Cardiology (ESC). Developed in collaboration with the European Heart Rhythm Association (EHRA). Europace 2013;2013:1070-118.

19. Goldenberg I, Moss AJ, Hall WJ, et al. Predictors of response to cardiac resynchronization therapy in the Multicenter Automatic Defibrillator Implantation Trial with Cardiac Resynchronization Therapy (MADIT-CRT). Circulation 2011;124:1527-36.

20. Hsu JC, Solomon SD, Bourgoun M, et al. Predictors of super-response to cardiac resynchronization therapy and associated improvement in clinical outcome: the MADITCRT (multicenter automatic defibrillator implantation trial with cardiac resynchronization therapy) study. J Am Coll Cardiol 2012;59:2366-73.

21. Kirkfeldt RE, Johansen JB, Nohr EA, et al. Complications after cardiac implantable electronic device implantations: an analysis of a complete, nationwide cohort in Denmark. Eur Heart $J$ 2014;35:1186-94.

22. Romeyer-Bouchard C, Da Costa A, Dauphinot V, et al. Prevalence and risk factors related to infections of cardiac resynchronization therapy devices. Eur Heart J 2010;31:203-10.

23. Riddell Tania. Heart failure hospitalisations and deaths in New Zealand: patterns by deprivation and ethnicity. $N Z$ Med $J$ 2004;118:U1254

24. Moss AJ, Hall WJ, Cannom DS, et al. Cardiac-resynchronization therapy for the prevention of heart-failure events. $N$ Engl J Med 2009;361:1329-38.

25. Khadjooi K, Foley PW, Chalil S, et al. Long-term effects of cardiac resynchronisation therapy in patients with atrial fibrillation. Heart 2008;94:879-83.

26. Gasparini M, Leclercq $C$, Lunati M, et al. Cardiac resynchronization therapy in patients with atrial fibrillation: the CERTIFY study (Cardiac Resynchronization Therapy in Atrial Fibrillation Patients Multinational Registry). JACC Heart Fail 2013;1:500-7.

27. Gasparini M, Regoli F, Galimberti P, et al. Cardiac resynchronization therapy in heart failure patients with atrial fibrillation. Europace 2009;11 Suppl 5:v82-v6. 
28. Go AS, Mozaffarian D, Roger VL, et al. Executive Summary: Heart Disease and Stroke Statistics-2014 Update. A Report From the American Heart Association 2014;129:399-410.

29. Higgins SL, Hummel JD, Niazi IK, et al. Cardiac resynchronization therapy for the treatment of heart failure in patients with intraventricular conduction delay and malignant ventricular tachyarrhythmias. J Am Coll Cardiol 2003;42:1454-9.

30. Looi KL, Gavin A, Sidhu K, et al. Utilization of cardiac resynchronization therapy in patients with heart failure in the Northern Region of New Zealand. J Arrhythm 2019;35:1-9.

31. Task Force C, Daubert J-C, Saxon L, et al. EHRA/HRS expert consensus statement on cardiac resynchronization therapy in heart failure: implant and follow-up recommendations and management $A$ registered branch of the European Society of Cardiology (ESC), and the Heart Rhythm Society; and in collaboration with the Heart Failure Society of America (HFSA), the American Society of Echocardiography (ASE), the American Heart Association (AHA), the European Association of Echocardiography (EAE) of the ESC and the Heart Failure Association of the ESC (HFA). Endorsed by the governing bodies of AHA, ASE, EAE, HFSA, HFA, EHRA, and HRS. EP Europace 2012;2012:1236-86.

32. Achilli A, Peraldo C, Sassara M, et al. SCART Study Investigators. Prediction of response to cardiac resynchronization therapy: the selection of candidates for CRT (SCART) study. Pacing Clin Electrophysiol 2006;29 Suppl 2:S11-S19.

33. Mastenbroek MH, Pedersen SS, Meine M, et al. Distinct trajectories of disease-specific health status in heart failure patients undergoing cardiac resynchronization therapy. Qual Life Res 2016;25:1451-60.

34. Tang AS, Wells GA, Talajic M, et al. Resynchronization-Defibrillation for Ambulatory Heart Failure Trial Investigators. Cardiacresynchronization therapy for mild-to-moderate heart failure. $N$ Engl J Med 2010;363:2385-95.

35. Huynh Quan L, Kazuaki N, De Pasquale Carmine G, et al. Determinants of Days Alive and Out of Hospital in Heart Failure. Circulation 2016;134. 